\title{
MONOAMINE OXIDASE ACTIVITY IN SOME BRAIN AREAS OF SHEEP AFTER HORMONAL STIMULATION
}

\author{
Bernadetta PÁstorovÁ, Angela StaníkovÁ, Marie MolnárovÁ, J. Halagan \\ and J. BULECA \\ Department of Physiology, University of Veterinary Medicine, Komenského 73, \\ 04181 Košice, Slovak Republic
}

(Received April 15, 1999; accepted June 24, 1999)

\begin{abstract}
The influence of hormonal superovulatory preparations Folistiman (450 IU FSH, Spofa, Prague) and serum gonadotropin (1500 IU PMSG, Spofa, Prague) on monoamine oxidase (MAO), the degradative enzyme of catecholamines, was investigated in some areas of the brain regulating reproductive functions (area preoptica of the hypothalamus, pituitary gland, and pineal gland) in ewes with synchronized oestrus (20 mg chlorsuperlutin) during the oestrous period using a radiochemical method. After intramuscular administration of 1500 IU PMSG, marked increase of MAO activity was found in the area preoptica $(p<0.05)$ and in the pituitary gland $(\mathrm{p}<0.01)$ in comparison with the control group. No change occurred in MAO activity after ovarian stimulation with FSH. Administration of the above superovulatory preparations failed to induce MAO activity in the pineal gland of sheep.
\end{abstract}

Key words: Monoamine oxidase, FSH, PMSG, superovulation, area preoptica, pineal gland, pituitary gland, sheep

The enzyme monoamine oxidase (MAO) plays an important role in the intracellular degradation of catecholamines by oxidative deamination and participates in the regulation of a functionally active pool of monoaminergic neuromediators in the presynaptic neurons. MAO exists in two forms, A and $\mathrm{B}$, di ffering from each other in substrate specificity and affinity to a number of i nhibitors. Oestrogens were found to be capable of modifying the activity of the degradative enzymes of catecholamines in the hypothalamus and in the striatum area in rats (Holzbauer et al., 1978; Yoshimoto et al., 1986). The administration of superovulatory preparations, particularly serum gonadotropins, is associated with a marked rise of blood plasma oestrogen levels in sheep. Mušicky and Lončar-Stepanovič (1987) observed changes in the activity of monoamine ox idase and adenylate cyclase with a parallel increase in cyclic adenosine mono-

*Fax: 095-767 675 
phosphate (cAMP) after the administration of human chorionic gonadotropin (HCG) and luteotropic hormone ( $\mathrm{LH})$.

Because of the scarcity of information available on the effect of hormonal preparations commonly used in the biotechnology of controlled reproduction on MAO in the hypothalamus, pineal gland and pituitary gland of sheep, we studied changes in MAO activity in these regions regulating the reproductive system of sheep after administration of FSH and PMSG.

\section{Material and methods}

The experiments were carried out on brain samples from 15 Slovak M erino sheep (age: $3-4$ years; average body weight: $46 \pm 4.4 \mathrm{~kg}$ ) in their oestrous period (September-October). Sheep were fed a standard molasses feed with v itamin additives twice daily. Oestrus was synchronized with intravaginal poly urethane sponges (Agelin, Spofa, Prague) containing $20 \mathrm{mg}$ of chlorsuperlutin, introduced for 12 days. On day 13 after insertion the sponges were removed, and FSH (Folistiman ad us. vet., Spofa, Prague) was administered to the first e xperimental group $(n=5)$ intramuscularly (i.m.) three times per day for two days with a total dose of 450 IU. Sheep in the second experimental group $(n=5)$ were hormonally stimulated by administration of 1500 IU PMSG (Bioveta, Ivanovice na Hané) i.m., in a single dose. The remaining five ewes served as control. The animals were killed by bleeding six days after removal of the sponges. Immed iately after slaughter, the brains were removed and samples were taken from the area preoptica, pituitary gland and pineal gland. The samples were stored frozen in liquid nitrogen until further pro cessing.

For the determination of MAO activity, tissues were homogenized in Potter-Elvehjem microhomogenizers in a sucrose solution $\left(0.25 \mathrm{~mol} \times \mathrm{l}^{-1}\right)$. The activity of MAO was determined in tissue homogenates $(25 \mu 1)$ radiochemically according to the method of Wurtman and Axelrod (1963). ${ }^{14} \mathrm{C}-5$-hydroxytryptamine of $18.5 \times 10^{-7}$ Bq.nmol ${ }^{-1}$ specific activity (Amersham, England), specific for the determination of total MAO activity, was used as a substrate in the amount of $6.25 \mathrm{nmol}$ per sample. Total MAO activity was measured in a Packard Tri Carb scintillating spectrometer in the ${ }^{14} \mathrm{C}$ channel. Proteins in the identical tissue homogenates were determined by the classic method of Lowry et al. (1951). The results were statistically evaluated by non-paired $t$-test as mean \pm SEM, in pmol products $\times$ mg protein ${ }^{-1}$. 


\section{Results}

The effects of FSH and PMSG treatment on brain tissues are shown in T able 1. Hormonal stimulation of sheep with 1500 IU PMSG caused a significant i ncrease in the activity of MAO $(\mathrm{p}<0.01)$ in the area preoptica of the hypothalamus from $6.02 \pm 0.52$ to $9.82 \pm 0.87$ as compared to the controls (Table 1). After the administration of 450 IU FSH no significant changes were observed in the a ctivity of MAO in the pituitary gland in comparison with the control group of synchronized oestrus. A significant increase in the activity of MAO from $2.03 \pm$ 0.19 to $2.91 \pm 0.28(\mathrm{p}<0.05)$ was observed in the pituitary gland following the stimulation of ovaries with PMSG. After the administration of $450 \mathrm{IU}$ FSH to the experimental sheep, no change was observed in the activity of MAO in the same area. No significant changes in the activity of MAO were recorded in the pineal gland of sheep following hormonal stimulation with PMSG and FSH.

Table 1

The activity of MAO $\left(\mathrm{nmol} \times \mathrm{mg}\right.$ proteins $\left.^{-1}\right)$ in the brain areas studied following hormonal stimulation of sheep with FSH and PMSG

\begin{tabular}{lccc}
\hline \multicolumn{1}{c}{ Nerve tissue } & $\begin{array}{c}\text { Control (Agelin 20 mg) } \\
(\mathrm{n}=5)\end{array}$ & $\begin{array}{c}\text { FSH (450 IU, Agelin) } \\
(\mathrm{n}=5)\end{array}$ & $\begin{array}{c}\text { PMSG (1500 IU, Agelin) } \\
(\mathrm{n}=5)\end{array}$ \\
\hline Area preoptica & $6.028 \pm 0.525$ & $8.320 \pm 0.765$ & $9.828 \pm 0.870^{* *}$ \\
Pituitary gland & $2.032 \pm 0.198$ & $1.987 \pm 0.120$ & $2.913 \pm 0.281^{*}$ \\
Pineal gland & $2.632 \pm 0.265$ & $2.956 \pm 0.250$ & $2.230 \pm 0.180$ \\
\hline
\end{tabular}

${ }^{*} \mathrm{p}<0.05 ;{ }^{* *} \mathrm{p}<0.01$

\section{Discussion}

Gonadotropins (PMSG, FSH, HCG) used for inducing superovulation in farm animals act on the steroidogenesis of ovaries and influence the hypoth alamic nuclei and their gonadotropic receptors by means of feedback mechanisms (Smolich et al., 1979; Pástorová and Várady, 1993, 1996). The administration of these hormonal preparations (most noticeably in the case of PMSG) is associated with hyperoestrogenism. High concentrations of circulating oestrogens act sp ecifically on the adrenergic receptors of the pituitary gland and affect the levels and metabolism of catecholamines in the central and peripheral adrenergic sy stem (Fernandez-Pardal et al., 1986; Pástorová and Várady, 1993, 1996). The direct administration of oestrogens to ovariectomized rats was demonstrated to cause an increase in dopamine turnover in the hypothalamic nuclei and a subs equent decrease in blood plasma LH (Pilotte et al., 1982). An increase in the activity of the catecholamine-synthesizing enzyme tyrosine- $\beta$-hydroxylase (Pilotte 
et al., 1982; Deaver and Dailey, 1983) was observed in parallel. Along with the changes in the metabolism of catecholamines through hyperoestrogenism some alterations in the activity of their degrading enzymes, MAO and catechol-omethyl-transferase (COMT), were also recorded after the administration of exog enous hormonal preparations (Yoshimoto et al., 1986; Pástorová and Várady, 1996).

$\mathrm{MAO}$ is an intracellular enzyme bound in the outer mitochondrial me mbranes and in the microsomal fraction of synaptosomes. Intraneuronal MAO plays an important role in the regulation of the functionally active pool of cat echolamines and serotonin and in the maintenance of their lowest cytoplasmic concentration in the presynaptic neurons (Holzbauer et al., 1978). Our previous studies revealed that the hormonal preparations used to induce superovulation in sheep elicit significant changes in the levels of hypothalamic and plasma cat echolamines (Pástorová and Várady, 1993, 1996). Their influence is different in individual hypothalamic areas regulating reproductive functions in sheep. Our experiment showed a significant increase in the activity of MAO in the area pr eoptica and pituitary gland after the administration of PMSG in comparison with the control and FSH-treated ewes. No effect of PMSG was observed in the pi neal gland. The administration of FSH had no effect on the activity of MAO in the ovine brain areas studied. In ovariectomized, HCG- and LH-treated rats, some authors (Deaver and Dailey, 1983; Nehr, 1991) found changes in the activity of MAO in ovaries and increased levels of cAMP, which they correlated with an increase in steroidogenesis after hormonal stimulation. The changes in MAO activity in the area preoptica and pituitary gland of sheep following PMSG stimulation are most likely related to hyperoestrogenism after the a dministration of PMSG, and to the fact that oestrogens modify the activity of the degrading enzymes involved in catecholamine metabolism (Holzbauer et al., 1978; Mušicky and Lončar-Stepanovič, 1987). We suspect that the changes observed in MAO activity in the brain areas studied are associated with changes in the levels of catecholamines observed in relation to steroid alterations after the administration of gonad otropic hormones.

\section{Acknowledgements}

This work was supported by grant VEGA $1 / 4230 / 97$. We would like to thank all the people who have helped us carry out this work. Particular thanks are due to Jana Jankurová for technical assistance. 


\section{References}

Deaver, D. R. and Dailey, R. (1983): Effect of ovarian secretion and dopamine secretion of luteinizing hormone and prolactin in ewes. J. Anim. Sci. 57, 978-984.

Fernandez-Pardal, J., Cimera, W. P. and Gimera, A. L. (1986): Catecholamine in sow graafian follicles at proestrus and diestrus. Physiol. Reprod. 34, 439-445.

Holzbauer, M., Sharman, D. F. and Godden, U. (1978): Observations on the function of the dopaminergic nerves innervating the pituitary gland. Neuroscience 3, 1251-1262.

Lowry, O. N., Rosenbrough, N. J., Fawr, A. J. and Randall, R. J. (1951): Protein measurement with the Folin phenol reagent. J. Biol. Chem. 193, 265-275.

Mušicky, B. and Lončar-Stepanovič, H. (1987): Concentration of circulating steroid hormones and catecholamines in the ovaries and uteri of rats with hypothalamic lesions. Period. Biology 89, 251-254.

Nehr, S. I. (1991): Effect of superovulatory dose of PMSG on uteri and serum steroid response in immature rats. Physiol. Reprod. 44 (Suppl. 1), 433-439.

Pástorová, B. and Várady, J. (1993): Effect of hormonal preparations on the activity of monoamine oxidase in uterus of sheep. Folia Veterinaria 37, 45-48.

Pástorová, B. and Várady, J. (1996): The effect of superovulatory preparations and FSH on the levels of catecholamines in blood plasma of sheep. Physiol. Res. 45, 125-129.

Pilotte, N., Burt, D. R. and Barraclought, S. (1982): Ovarian steroids modulate the release of dopamine into hypophyseal portal blood. Endocrinology 114, 2306-2311.

Smolich, T., Schauer, D., Weber, G. and Busch, W. (1979): Morfokinetische Wirkung on PMSG and Sexualsteroiden auf glieder der Zerebro - Hypophyseo - gonadalen Achse anesterische Schafe. Arch. Exp. Veter. Med. 33, 141-149.

Wurtman, J. and Axelrod, J. A. (1963): A sensitive and specific assay for the estimation of monoamine oxidase. Biochem. Pharmacol. 12, 1434-1440.

Yoskimoto, Y., Sakumoto, T., Rychachi, A. and Miyake, A. (1986): Monoamine oxidase in rat ovary during the estrous cycle. Endocrinology 119, 1800-1804. 